\title{
Diásporas, homogeneidades e pertenças entre os Tembé Tenetehara de Santa Maria'
}

\author{
Jane Beltrão \\ Universidade Federal do Pará \\ Rhuan Carlos dos Santos Lopes \\ Doutorando do PPGAS \\ Universidade Federal do Pará
}

Resumo: Considerando as transformações impostas às práticas de produção cultural e organização política da pertença Tenetehara, interroga-se como o povo Tembé dito de Santa Maria, enfrentaram e enfrentam a diáspora promovida, no século XIX, pelo Estado aliado à Igreja Católica, para afirma-se, hoje, como povo indígena. Analisam-se ações para recriar o "coletivo". Para tanto, as marcas "tomadas como étnicas" são sublinhadas nos documentos e observadas no quotidiano, pela diferença que produzem em relação aos "vizinhos" não-indígenas que cercam os pequenos "territórios" que os Tembé conseguiram preservar.

Palavras-chave: Diásporas, Coletivos indígenas, Pertenças, Identidades étnicas. 


\title{
Diasporas, homogeneities and belongings among the Tembé Tenetehara of Santa Maria
}

\begin{abstract}
Considering the transformations imposed on the cultural production and political organization practices of the Tenetehara belonging, we question how the Tembé people from Santa Maria, faced and face the diaspora, promoted in the 19th century by the State allied to the Catholic Church, to assert themselves as an indigenous group. We analize the actions to recreate the collectiveness. In order to do so, the marks "considered as ethnic" were underlined in the historical documents and observed in everyday life, by the difference made regarding the non-indigenous "neighbors" that sorround the small "territories" the Tembé were able to preserve.
\end{abstract}

Key Words: Diasporas, Indigenous collectiveness, Belongings, Ethnical identity.

\section{Diásporas, homogeneidades y pertenencias entre los Tembé Tenetehara de Santa María}

Resumen: Considerando las transformaciones impuestas a las prácticas de producción cultural y organización política de la pertenencia Tenetehara, se interroga cómo el pueblo Tembé dicho de Santa María, enfrentaron y enfrentan la diáspora promovida, en el siglo XIX, por el Estado aliado a la Iglesia Católica, para afirmarse hoy, como pueblo indígena. Se analizan acciones para recrear el colectivo. Por lo tanto, las marcas "tomadas como étnicas" son subrayadas en la documentación histórica y observadas en la cotidianidad, por la diferencia que producen en relación a los "vecinos" no-indígenas que cercan los pequeños territorios que los Tembé consiguieron preservar.

Palabras-clave: Diásporas, Colectivos indígenas, Pertenencias, Identidades Étnicas. 


\section{Diásporas “orquestradas” entre Estado e Igreja}

Usa-se diásporas no sentido de dispersão para referir as migrações compulsórias (Benbassa, 2010) às quais os Tembé Tenetehara ${ }^{2}$ foram submetidos, ainda no século XIX, quando o Estado aliado à Igreja Católica decidiu criar o Núcleo Colonial Indígena no Prata (Pará-Brasil). Considera-se que a migração forçada produziu uma ruptura traumática aos Tembé com o território original e consequentemente a inscrição da identidade ficou restrita às narrativas que, há muito, alimentam os projetos de vida em comum, como forma de manter presente, a cultura que compreende crenças e hábitos que os mantém unidos e diferenciados em relação aos não-indígenas, apesar da maciça homogeneização a qual foram submetidos.

A categoria diáspora permaneceu restrita, durante anos, à situação vivida pelo povo Judeu e pelos povos Africanos escravizados pelos europeus, postura que implica em considerar o que acontece no continente Americano como de importância menor, especialmente, porque se refere aos povos originários leia-se indígenas. Hoje, o preconceito trazido pelo eurocentrismo às Ciências Sociais precisa ser desfeito, pois a ação colonial na América foi deletéria e, ainda, produz discriminações hediondas que merecem tratamento acadêmico adequado. Como antropólogos situados na América, considera-se necessário analisar politicamente o caso, tentando retirar as vendas que tentam evitar o olhar arguto e revelador.

Em cinco anos de contato, mais próximo com os Tembé de Santa Maria, em face de interesses comuns relativos à escrita da história do povo, muitas têm sido as conversas para produzir o material, pois entre os sonhos comunitários, como informa Cauã, estão a "demarcação de nossas terras, ... boa educação dentro da comunidade, e bom recurso para que possamos ter uma boa saúde e outros benefícios para nosso povo.”3

\footnotetext{
${ }^{2}$ Conserva-se as palavras em itálico pela origem não-portuguesa dos vocábulos e, escreve-se no singular, porque por convenção não se faz o plural de nomes indígenas pelo desconhecimento das regras de uso dos plurais. Grafa-se Tembé em maiúsculas quando se refere ao povo e em minúsculas quando adjetivo, em ambos os casos em itálico.

3 Partes dos trechos de registro escrito, apresentados no trabalho, correspondem às provas de língua portuguesa do Processo Seletivo Especial, ocorrido em 2010, para povos indígenas, na Universidade Federal do Pará (UFPA). Considerando que as provas - mesmo quando documentos disponíveis à pesquisa - não permitem ao estudioso ter acesso aos nomes dos autores, pois as provas só são identificadas em um momento durante o processo seletivo, quando se precisa oferecer os conceitos. Assim sendo, ao usar os depoimentos dos candidatos não se revela a identidade dos interlocutores, mas para conferir fluência ao texto, atribuí nomes fictícios aos escritores. As transcrições das histórias mantiveram a estrutura do português falado pelos Tembé, pois embora não mais falem o Tenetehara o português falado entre os membros da comunidade é diferenciado do português praticado na Academia, traduzir produziria mutilação na expressão Tembé, proibidos que foram de praticar a língua materna, desde o final do século passado, quando foram sujeitados a ação dos Capuchinhos Lombardos no Núcleo Colonial Indígena.
} 
No trabalho, procura-se apresentar as histórias 4 e os sentidos da pertença tembé, que indicam o território tradicionalmente ocupado - ontem e hoje - e os direitos diferenciados que demandam diuturnamente, via ação política, na maior parte das vezes, conduzida pela Associação Indígena Tembé de Santa Maria (AITESAMPA) que luta entre indígenas para ter adesão à causa, e entre não-indígenas para se fazer respeitar como povo indígena.

Conjugam-se as histórias narradas para indicar o lastro que oferecem aos projetos de "viver na comunidade" para "melhor viver", apesar das histórias e projetos de vida comunitária continuarem sendo, como ensina Cauã, “... um pequeno resumo de uma história sofrida [pelo] meu povo." Em pouco mais de um século do final do XIX ao XXI, os Tembé se viram despojados de suas terras e circunscritos a espaços que dificultam o desenvolvimento comunitário, pois pelejam em meio aos não-indígenas que cercaram as terras que conseguiram manter.

As narrativas tembé são tomadas como verdades pelo poder que a palavra e a performance do narrador tem de mobilizar autoridade enquanto falante que sabe, conhece dentro da comunidade, pois as histórias são ditadas pela memória e "recitadas" a partir do emaranhado cultural que cultivou a resistência ao processo de homogeneização ao qual estiveram expostos. A solicitação de escrita das "histórias" narradas é a demanda, pela compreensão de que parte do preconceito que conduz à discriminação, a comportamentos anti-indígenas, pode ser suavizado a partir da história escrita, pois os Tembé conhecem a importância que a linguagem da História, possui na comunicação e que a mesma reafirma, na/pela escrita, a identidade que os demais (não-indígenas e, mesmo indígenas) acreditam que se esvaiu. (Gnerre, 2003 e Goody, 1988)

Ao falar em vida comunitária, os tembé imaginam-se um grupo de pessoas que compartilham histórias, mesmo que não mais falem Tenetehara, ainda comungam de valores e objetivos comuns, reconhecendo a mesma pertença e solidariedade, embora existam conflitos decorrentes do processo de homogeneidade.

Miguel, cacique da aldeia Areal, é exímio narrador e ao contar histórias é sempre ouvido com atenção. Ao conhecê-lo prestamos bastante atenção ao pronunciamento que fez durante a primeira reunião que participamos entre os Tembé. Miguel investido de sua autoridade de mais velho, ao usar da palavra informou que para voltar a viver em paz com todos esses seres que nos envolvem - falava de humanos e não-humanos - torna-se urgente que “... o território seja demarcado ...”, pois só assim poderiam praticar as tradições dos antigos: os rituais, a caça, a pesca e as atividades quotidianas, pois estas seriam realizadas em ambientes adequados "... garantindo nossa continuidade física e cultural." E, na sequência, narrou a "História da Guariba", fazendo um paralelo 
entre a história e a realidade da comunidade e a forma como as "coisas" aconteceram entre os Tembé.

\begin{abstract}
"[é] na primeira vez que eu fui participar da teologia [reunião do Conselho Indigenista Missionário], aí o rapaz 'tava contando as histórias, aí eu disse mas oh rapaz! Olha aqui, daí pediram pra conta o meu história, aí contei, daí no final eu achei a nossa luta idêntica com a da Guariba, né? Porque a Guariba é o seguinte: ela perdeu todos os pais, né? E aí ficou. Hoje, nós temos um exemplo aqui com os filhos da Maria né, a Maynumi, perdeu o pai, ninguém sabe quem é o pai, a mãe não sabe, não sabe quem é a mãe, quando ela toma conhecimento da vida né? Aí ela vai, não vai ter conhecimento nem da mãe e nem do pai, e aí é um modo idêntico a situação da menina né? Porque olha, a preguicinha perdeu todos os pais, ficou recém nascida, criada pelos outros, Guariba é um macaco, e aí o que que acontece, quando ela se formou-se que tinha os seus 15 anos, saiu procurando qual era, cumô é que o pai dele cantava, aí ninguém sabia, um informava diferente, outro informava de outro jeito e não tinha jeito nenhum pra encontrar, aí a Guariba chegou na casa da preguiça, ia passando, e lembro de perguntar camarada preguiça, você sabe me contar cumô era que meu pai cantava?”
\end{abstract}

Como a Guariba (símbolo da esperteza), os Tembé "perderam” os pais, ainda crianças (inversão da ordem "natural" da vida), arrancados que foram pelos missionários lombardos para integrarem as escolas/internatos, onde deveriam se civilizar. A perda informada indica a necessidade de "escutar o canto do pai", mas escutar não é tarefa fácil, pois não "lembram" mais e, pouco ou nem "sabem cantar".

Na sequência, Miguel conversando vagarosamente, disse que a preguiça (símbolo da paciência) respondeu: "eu sei!" E a Guariba, afoita disse "como é?" Ao que a Preguiça respondeu:

"[o]lha deixa eu termina de pentiá meu cabelo, e eu vô lhe ensina, pra você como é que o teu pai cantava, aí terminou de pentiá o cabelo, aí disse: agora nos vamo pra acolá. Subiram num pau alto aí, a Guariba atenta ouviu, a Preguiça que começou a cantá."

O cantar exige paciência (espera associada à sabedoria de resistir), pois não se canta numa ocasião qualquer, e a ação requer preparação (torna-se bela, penteando os cabelos), além de requerer lugar reservado (acolá, no alto do pau), longe dos olhos dos demais, talvez para evitar repreensão que obriga a "não cantar”.

E, Miguel observou ainda:

\begin{abstract}
"porque a preguiça é real, ela canta igualmente a Guariba só que ela não droba [dobra] né? aí ... a preguicinha, não droba, ela faz uaaaaaaa e a Guariba ela droba uaaaaaoooooouaouaouao, aí o Capelaozão, aí a bicha não, ela faz uaaaaaaaaa, aí terminou, aí disse: era assim que o teu pai cantava. Aí a preguicinha se abraçou-se com a Guariba que se abraçou-se com a Preguiça, e agradeceu muito e chorou porque se emocionou-se, né? E agora eu vô me embora. Não, eu tenho uma menina aí, tá moça e você vai casá com ela, aí a Guariba casou-se com a Preguiça e transformou-se em uma nova geração, a Preguicinha e a Guariba que tiveram uma família, aí começou uma nova geração."
\end{abstract}

Ao despertar para o canto, Miguel relembra formas e nuances entre o ser Tembé e o ser o outro, apontando as diferenças que às vezes não passam de 
nuances que só um verdadeiro Tembé pode reconhecer e ensinar aos mais jovens.

Prossegue Miguel “... é aí! Como eu achei idêntica com a nossa luta”, especialmente,

\begin{abstract}
"porque nóis 'tava, eu praticamente 'tava, eu 'tava ali naquele momento eu vi como era ... correto o que povo, a gente era né? Porque, disseram que a gente era Tembé, porque minha mãe não dizia prá gente, só dizia que a gente era Tembé, mas não dizia qual era a etnia, qual não sabia, e aí quando eu vi pela fala do ... Tenetehara, contando a história da Mucura, como é que meu pai cantava, o Bacural, e dizê, é Tembé mesmo nós 'tamo aqui já procurando tê o conhecimento do nosso povo, e aí que por isso no final da história, diz, é uma luta! Assim como nós estamo procurando tê formação da nossa história né? E, é correto que deu tudo certo, e a história da Guariba, essa historia da Guariba minha mãe contava muito, e tinha outros e outros histórias que ela contava que eu num gravei, mas tinha muito, muito, eu sei só assim os pedacinho, que nem o mito da Capivara, né? da Capivara."
\end{abstract}

É importante ressaltar, a história narrada por Miguel, pelo lugar que ele ocupa entre os Tembé, uma vez que reflete sobre a realidade vivenciada pelos interlocutores. Como refere Almir (2012), presidente da Associação,

“... durante muito tempo tivemos que nos esconder, esconder nossa identidade e negar que éramos indígenas, nossos pais sofreram muita discriminação e nós continuávamos sofrendo, mas enfrentando todas as adversidades e as situações que poderiam surgir, resolvemos buscar a nossa história, saber realmente como é que nossos pais cantavam."

A "História da Guariba" que o cacique Miguel conta, relembrando que perdeu seus pais quando ainda era criança, diz respeito ao "tempo dos antigos" que só a memória alcança. Tempo o qual, em suas preleções, refere aos mais jovens e as crianças, sempre que se dispõe ou é solicitado a "contar histórias". Conta que certo tempo depois, quando tornou-se rapaz procurou saber a história do povo e, na busca, procurou muitos (pessoas mais velhas) que talvez pudessem informar sobre o passado e sobre "como é que seu pai cantava", muitos informaram como era o canto do seu pai, mas ele não se identificando com os relatos, continuava a busca, procurou, procurou até encontrar a Preguiça (vagarosa e paciente) que, relembrou como era que o pai de Miguel cantava, e foi assim que a Guariba (com a sagacidade que lhe é peculiar) relembrou como era que o seu pai cantava. Miguel inclui em seus relatos a lição moral: não se pode confiar em qualquer canto, apenas um deles é verdadeiro. Portanto, um único era Tembé.

"A história reflete a realidade vivida pelo nosso povo", diz Almir - que aprendeu com Miguel, as histórias da tradição - muitas foram as investidas sobre nosso povo e nosso território com o objetivo de

“... fazer com que a gente deixasse de ser Tembé, deixasse de falar a nossa língua, de praticar nossa cultura, foram várias estratégias para ... nos fazer esquecer o nosso passado, mas hoje estamos aqui, procurando saber de diversas formas e por intermédio de outras pessoas conhecer nosso passado [ou seja] como é que os nossos pais cantavam." 
O cacique Miguel ao narrar o passado indica que sua mãe ao falar quem eram, sabia que eram indígenas, mas não sabia qual era o povo ao qual pertenciam, ela em suas lembranças falava que era de um povo conhecido como Timbé [Tembé],5 mas depois de conhecer nossa história é que fomos descobrir nossas origens e a quem estamos ligados. Afinal, perderam os pais muito cedo, não tiveram tempo de aprender.

Antigamente, informa Almir, quando os Tembé tinham domínio do território, a relação com os antepassados e com os seres encantados era mais próxima, segundo os relatos. Era comum que os Tembé nas caçadas sofressem com as artimanhas do Curupira e com a "aparição" de outros seres encantados. Contam os mais velhos que cresceram ouvindo histórias contadas, pelos avós, sobre o Curupira que, também, é conhecido com pai da mata, é ele quem guarda a floresta e cuida dos animais feridos. O passado corresponde aos anos de ouro, ao passado que foi bom em contraponto aos dias de hoje que são sofridos e com quase nenhum reconhecimento. O território para os Tembé é o lugar da expressão cultural.

A presença dos seres encantados nas histórias contadas pelos mais velhos está fortemente ligada ao território e a existência de floresta, pois é na terra e na mata que moram, os seres que os interlocutores consideram sagrados e informam haver conexão entre os Tenetehara e os antepassados, o espírito dos ancestrais; e com os animais e os seres encantados. Há interdependência entre eles: território e gentes; gentes e demais seres encantados ou não; a relação de interdependência, inclusive, produz a continuidade da existência. Favorece a vida em comunidade.

Território, segundo a representação Tembé, é compreendido não apenas como um espaço geográfico, pois se confunde com a própria casa. É o local onde se vive a cultura; é o lugar do povo, onde se vive em comunidade; ou seja, é espaço de afirmação identitária. E, como não são mais ou ainda senhores do território imemorial, informam:

\footnotetext{
“[a] nossa cultura não esta totalmente completa, falta-nos a nossa mãe terra, a nossa língua ainda existem pessoas na nossa aldeia que conhecem palavras soltas e os nossos rituais. Queremos reacender esta cultura e para que isso venha acontecer precisamos conquistar de volta o nosso território.” (Relatório do Povo Tembé).
}

Portanto, a principal demanda pelo "melhor viver" e viver em comunidade é o território e, embora, não sejam senhores dos espaços imemoriais de antes, que hoje são ocupados por terceiros, não desistem de reivindicar a demarcação do território tradicionalmente ocupado como indica a Constituição Brasileira de 1988.

\footnotetext{
5 Tembé ou a variante Timbé foi denominação, provavelmente, atribuída pelos não-indígenas. Os Tembé constituem o ramo ocidental dos Tenetehara, autodenominação que significa gente, índios em geral ou, mais especificamente, gente Tembé. Sobre o assunto, conferir: http://pib.socioambiental.org/pt/povo/tembe/10211. Acesso em: 01.04.2012. Ou, como resume, Almir Vital da Silva, tembé estudante de enfermagem da UFPA e liderança política do povo Tembé, em seu relatório de Iniciação Científica: “[s]omos da família linguística Tupi-Guarani, do Tronco Tupi, conhecidos pelos parentes como Tembé de Santa Maria do Pará, não somos muito conhecidos pela literatura etnológica nacional. A História Tembé, assim como maioria dos povos indígenas do Brasil é marcada por transformações produzidas pelo contato com os não-indígenas, que nem sempre chegou a bom termo" (2012: 6).
} 


\section{Homogeneidade articulada, identidade sufocada}

No Brasil, o uso da força contra os povos indígenas que produziu o genocídio dos primeiros tempos estava supostamente proscrita, pois a política, à época, era ampliar e proteger as fronteiras nacionais conquistando, via colonização, os territórios em poder dos indígenas, entretanto a execução do projeto do etnocídio, supostamente cordial, que produzia a homogeneização pela ótica colonialista na esperança de morigerar os então chamados silvícolas. O Pará, não fugiu a regra, como informa Palma Muniz:

“... foi resolvido enfrentar o importante problema social da catequese [dos indígenas]
disseminados na zona dos rios Capim e Guamá [território indígena Tembé
Tenethehara], sem outro caloulo que o sacrifício e a lucta, sem mais outro fim que a
chamada ao grêmio christão e catholico de almas perdidas nas selvas, e levar a outros
tantos brasileiros abandonados, não só os contornos da civilização, como assegurar-
lhes todas as proctecções da nossa legislação.” $(1913: 5$, sic.)

Para dar conta da recomendação, “... as largas vistas ...” do então presidente da Província do Grão-Pará, Paes de Carvalho, avalizou os Capuchinhos Lombardos da Missão do Norte, situada no Maranhão, no Brasil, a implantar um Núcleo Colonial Indígena, no Pará, com finalidade especial de "cathequese dos silvícolas". (Muniz, 1913: 6, sic.)

Os Capuchinhos implantaram o Núcleo no, hoje, município de IgarapéAçú (Mapa), às margens do rio Prata, com a promessa de se deixar ficar por um período de 15 anos, conforme a orquestração acordada politicamente. A localidade distava seis dias de Belém e a Estrada de Ferro de Bragança, em construção, alcançava a vila do hoje município de Castanhal (Pará), fato que deixava a questão das comunicações razoavelmente solucionadas, pois o caminho de ferro correspondia à metade do percurso entre Belém (capital) e o Prata. 


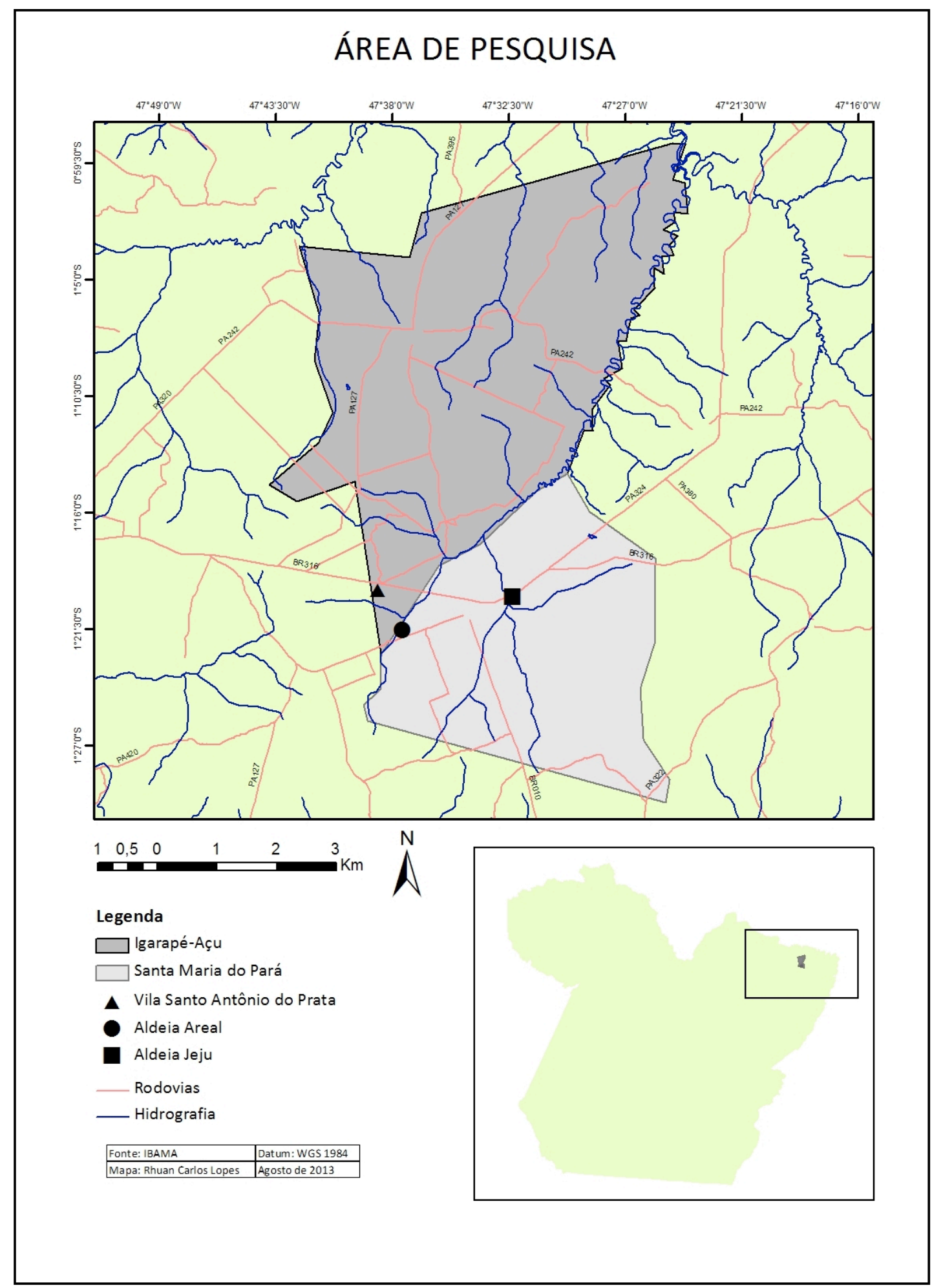

Segundo a Lei №. 588 de 23 de junho de 1898, a Missão Capuchinha deveria: (1) ministrar ensinamentos da catequese católica; (2) dar instrução elementar; e (3) preparar mão-de-obra aos trabalhos agrícolas. Entre os planos do Núcleo estavam previstas as instalações físicas compreendendo: edifícios para a Igreja e próprios administrativos; internatos escolares para meninos e meninas (indígenas e órfãos); casas de colonos; campos experimentais; engenho 
de cana; e estação de ferro carril. Espaço planejado para controlar, adequadamente, os imorigerados Tembé.

A descrição, permite pressupor os impactos da Missão Capuchinha, especialmente, considerando que, a área era território indígena e quilombola de amplas dimensões no século XIX. A "Cruz redemptora da humanidade", implantada por Frei Carlos de São Martinho, em 14 de setembro de 1898, dá início à cordialidade catequética que conduz ao etnocídio.

A comprovação do território multiétnico (indígena e africano), compreendendo comunidade multiétnica que vem a ser a emergência e consolidação de organização social de etnias de tamanho e composição diversa e flexível. Comunidade forjada pelo encontro de indígenas (donos da terra) e africanos que se refugiavam em espaços indígenas por serem distantes e pouco acessíveis às tropas de resgate que buscavam braços para escravizar ou africanos fugidos do jugo das autoridades coloniais. Há referência a confederações multiétnicas no Rio Negro na literatura corrente, especialmente, na Venezuela (Wrigth, 2005). No caso estudado, as referência à comunidade multiétnica, chega a nós, via Palma Muniz que informa:

“[r]esa a tradição, encontrada entre os índios que em tempos idos, talvez em eras coloniaes ainda, a região das nascentes do maracanã, então não taladas pelas incursões civilisadoras, serviu de refugio a escravos fugidos, tanto das terras do rio Guamá, como das costas atlanticas, e de Belém e suas cercanias, que, internando-se nas mattas, desaparecem para sempre." (1913:16, sic.)

E, prossegue, informando que:

"[e]xistiu néssas paragens um célebre mocambo de negros que cultivavam a terra e viviam da caça, fazendo de quando em vez correrias nos povoados e fazendas das circumvizinhaças,, deixando atraz de si a rapina, o assassinato e outros crimes, acolhendo-se aos seus reductos, que defendiam de qualquer espionagem $\mathrm{e}$ conhecimento, tendo feito pagar com a vida todo aquelle que se aventurou a conhecer-lhes a localização." (Muniz, 1913:16, sic.)

A considerar as observações de Palma Muniz (1913) a área era conflagrada e, segundo as indicações, localizava-se acima do Prata e denominava-se Santa Maria de Belém, às margens direita do rio Maracanã. A repressão aos negros amocambados foi enérgica, leia-se dizimadora, produzindo grande mortandade e destruindo o mocambo. O domínio colonial inviabilizou o projeto territorial de povos nativos, no caso os Tembé; e de povos transplantados, como os africanos escravizados, a diáspora estava promovida uma vez mais. Entretanto, os casamentos inter-étnicos tornam inúmeros descendentes da comunidade original Tembé em pessoas, facilmente, identificadas como negras, pelo fenótipo, sinal diacrítico que remete à discriminação que sofrem na atualidade, pois para o senso comum "índios não são negros". A construção é recorrente na sociedade brasileira, embora como afirma Oliveira Filho: [o]s [povos] indígenas não tem homogeneidade cromática, nem possuem traços físicos que possam singulariza-los perante outros segmentos da população.” (1999: 134). Ao fazer a afirmação sobre a negritude dos Tembé as pessoas esquecem a possibilidade do 
estabelecimento de relações sociais entre os grupos étnicos, negando os direitos de ultrapassar fronteiras étnicas e a dinâmica do convívio tradicional que se renova. (Barth, 2000).

O suposto desaparecimento do mocambo levou os indígenas a se assenhorear uma vez mais do território, provavelmente, acolhendo os negros que sobreviveram à repressão e formando uma nova aldeia a uma légua da então Colônia do Prata, que abandonada pelos Capuchinhos tornou-se Casa de Correção e, posteriormente, veio a transformar-se em Leprosário, conhecido como Colônia do Prata. A saída junto com os aliados seria uma das muitas maneiras dos Tembé de livrar-se da homogeneidade a que foram submetidos. A ação estratégica é lida por Muniz (1913) como fuga.

Ainda, segundo Muniz (1913), o novo espaço era conhecido como Aldeia Velha, hoje, de saudosa memória no relato dos mais velhos que, vez por outra, falam do lugar com alguma nostalgia a partir da lembrança de histórias contadas pelos pais, avós e bisavós repassadas de geração a geração. É fato, portanto que, os donos da terra rearranjavam o território em função das vicissitudes produzidas pelo embate com os invasores.

Diz ainda, o cuidadoso historiador, sobre os amocambados que, o tempo se encarregou de fazer crescer o "célebre mocambo", o qual teria chegado a compreender 1000 almas, fato que os levou a "construir uma aldeia" que abrigava: africanos escravizados fugidos, criminosos evadidos da justiça e, mais tarde índios, incorporados após a destruição. Um lugar criado à revelia do Estado só poderia abrigar pessoas que para o Estado, são sem qualificação.

Muniz (1913) refere-se de forma explicita às comunidades multiétnicas pouco estudadas - existentes em território paraense e na Amazônia, as quais se afiguravam poderosas e que o Estado não podia suportar. Por certo, daí decorre a insistência em morigerar os povos que viviam entre os rios Guamá e Maracanã, pois o território supostamente pertencia ao Pará, mas fugia das mãos do Estado e produzia danos insuportáveis, afinal como os ditos civilizados não conseguiam domar (ou amansar, como se dizia à época) gentes não-civilizada, ou sejam indígenas e africanos.

No local, onde no passado se produziu a infraestrutura do Prata, encontravam-se: (1) as casas, em número de cinco ou seis, dos índios da família Miranha; (2) em Anselmo, à margem esquerda do rio Maracanã viviam os Tupanas; (3) a família Braz morava no Jeju, afluente da margem direita do rio Maracanã; e (4) em Arrayal, nas nascentes do rio Jeju ficavam a família dos Leopoldinos, segundo Muniz: “[t]odas estas familias pertenciam a tribú Tembé e viviam em contínua relação entre si, e ultimamente [à época da construção do Prata] com civilisados, por intermedio dos respectivos chefes." (1913: 16/17, sic.)

Os Tembé, portanto, sempre estiveram em Santa Maria, mas a cidade chegou a eles, incialmente, como Núcleo de Colonização Indígena, depois elevada a categoria de Vila e, mais adiante à sede de município. A cidade ocupou a aldeia dos Braz e dos Leopoldinos, famílias consideradas as mais antigas entre os Tembé. 
Portanto o "melhor viver", para o povo Tembé requer retorno ao território, pelo menos ao, hoje, território tradicionalmente ocupado e garantia de demarcação do mesmo é o projeto de vida em comum que mantêm os descendentes dos Braz e Leopoldinos, o qual é ensinado coletivamente por diversas vias.

\section{Criança, perdi meu pai e minha mãe}

Para os Tembé de Santa Maria as narrativas do cacique Miguel são importantes para a reafirmação da identidade, mas insuficientes para se fazer respeitar como povo indígena que são, por isso há mais de dez anos procuram: (1) reunir documentos, (2) escrever relatórios, (3) adentrar ao ensino superior (o mundo escolar dos brancos) e (4) terceiros - com quem possam produzir parcerias - e solicitam serviços para dar a conhecer aos demais, por intermédio da escrita, a História dos Tembé de Santa Maria. (Beltrão, 2012; Fernandes; Silva \& Beltrão, 2011)

O genocídio e o etnocídio perpetrado contra os Tembé é reconhecido, nas histórias narradas, como a "perda dos pais", registrada na História da Guariba quando se diz:

“... é o seguinte: ela perdeu todos os pais, né? E aí ficou. Hoje, nós temos um exemplo aqui com os filhos da Maria né, a Maynumi, perdeu o pai, ninguém sabe quem é o pai, a mãe não sabe, não sabe quem é a mãe, quando ela toma conhecimento da vida né?”

Considerando a proposta feita pelos Tembé, estamos em busca de como a documentação que existe sobre o antigo Núcleo Colonial Indígena pode demonstrar, via indícios, entendidos aqui como possibilidade de produzir hipóteses referentes a afirmação "criança, perdi meu pai e minha mãe" que a rigor pode ser repetida por qualquer uma das pessoas tembé de qualquer idade. Os mais velhos pela autoridade do conhecer e os mais jovens pelo que aprendem com os velhos conhecedores a ser Tembé Tenetehara.

Uma das possibilidades encontrada de atender a demanda dos Tembé foi trabalhar com a documentação que restou entre as ruínas do Prata. Escolha que se relaciona ao silêncio das fontes e da historiografia a respeito do destino dos povos indígenas, antes, confinados no Núcleo Colonial Indígena. Para onde foram as pessoas tembé? Foram expulsas? Deixaram-se ficar nas imediações? Fugiram para espaços distantes? Foram considerados hóspedes/reclusos da casa correcional que substituiu o educandário católico? Sofreram com mais uma diáspora? São perguntas que não querem calar, mas para as quais não temos até então respostas. Ao lidar com a documentação procuram-se o registro da passagem das famílias: Miranha, Anselmo, Tupanas, Braz e Leopoldino pelo Prata. A tarefa é árdua, pois os nomes das famílias devem ter sido atribuídos ou escolhidos quando da conversão, mas o dar um nome cristão fazia parte dos registros nos núcleos desde a Colônia.

Pelo comportamento diplomático Tembé Tenetehara as narrativas ganham espaços e as migrações forçadas do tipo diásporas aparecem por 
intermédio de metáforas, como as que se descrevem acima. Portanto, como acadêmicos parceiros devemos revelar os enlaces e demonstrar as violências produzidas pela política homogeneizadora, pois é essa inscrição que auxiliará os Tembé a manter viva a reivindicação pelo território.

Assim, trabalha-se o livro de Registro dos Attestados de Obitos ocorridos na Lazaropolis do Prata (sic) aberto em outubro de 1923, ano anterior à fundação oficial da Instituição asilar. Cujo primeiro óbito foi registrado em 22 outubro de 1923, relativo a Ernesto Viriato Soares, recolhido em 30 de junho de 1923 (Registro dos Attestados de Obitos ... 1923-1938: 1). Como nos outros 738 registros até 1938, segue-se roteiro de informações essenciais acerca do paciente falecido: número do óbito, nome do sujeito, causa mortis, data e hora da morte, idade, cor da pele, nacionalidade, estado civil, naturalidade, filiação e indicação de vida ou morte dos pais, indicações de lepra entre os pais, data de acolhida (recolhimento à instituição), número da internação, matrícula e local do Serviço Geral, espólio, local de sepultamento e, por fim, assinatura dos médicos responsáveis. A sequência de dados permitem inferências diversas, pois os atributos dão o tom de objetividade ao documento, tal como é possível observar nas Fichas que regiam a vida dos doentes no Prata. Todavia, a ausência de um ou outro apanágio, de acordo com o assentamento dos mortos, sugere a dimensão subjetiva presente nas tintas médicas.

A ausência de objetividade, como destacou Ginzburg (1990 [1976]), não anula a validade da fonte. Pelo contrário, possibilita a verificação/interpretação centrada nos "... resíduos, sobre dados marginais, considerados reveladores. Desse modo pormenores normalmente considerados sem importância e até triviais, "baixos" forneceriam a chave para aceder aos produtos ..." (Ginzburg, 1990 [1976]: 147-148) que, no caso específico, permite a aproximação com as representações médicas acerca da doença e do atendido (Cardoso, 2000), além da tentativa de reconhecer os indígenas entre os doentes e os não-doentes.

Considera-se que as narrativas dos profissionais possuem historicidade reveladora de preceitos (Cardoso, 2000) que no passado podem ter apoiado ações discriminatórias em função desse ou daquele apanágio. Tendo em vista os objetivos do trabalho, ora apresentado, problematiza-se os marcadores sociais da diferença, no caso aqueles de natureza étnico-racial dos mortos que mereceram registro.

A pesquisa encontra-se no início. No trabalho, discute-se a partir de cem sujeitos cujos registros e informações foram tabulados e, nos quais aparecem proporcionalmente as seguintes referências: $50 \%$ brancos, $45 \%$ mestiços, $2 \%$ pretos, sendo que $2 \%$ não tiveram a etnia informada. Todos os mestiços e pretos, além dos não informados, são marcados como brasileiros, o que implica na classificação aos estrangeiros (espanhóis, portugueses e sírios) como brancos (Gráfico 1). Essas pessoas de cor são advindas, sobretudo, do Pará e do Ceará, posto que do primeiro estado viessem $53 \%$ dos indivíduos e do segundo, $16 \%$ (Gráfico 2). Sabe-se que, com a construção da Estrada de Ferro de Bragança, 
espanhóis e sírios libaneses estabeleceram-se ao longo da ferrovia, bem como entre os trabalhadores da mesma encontravam-se muitos cearenses.

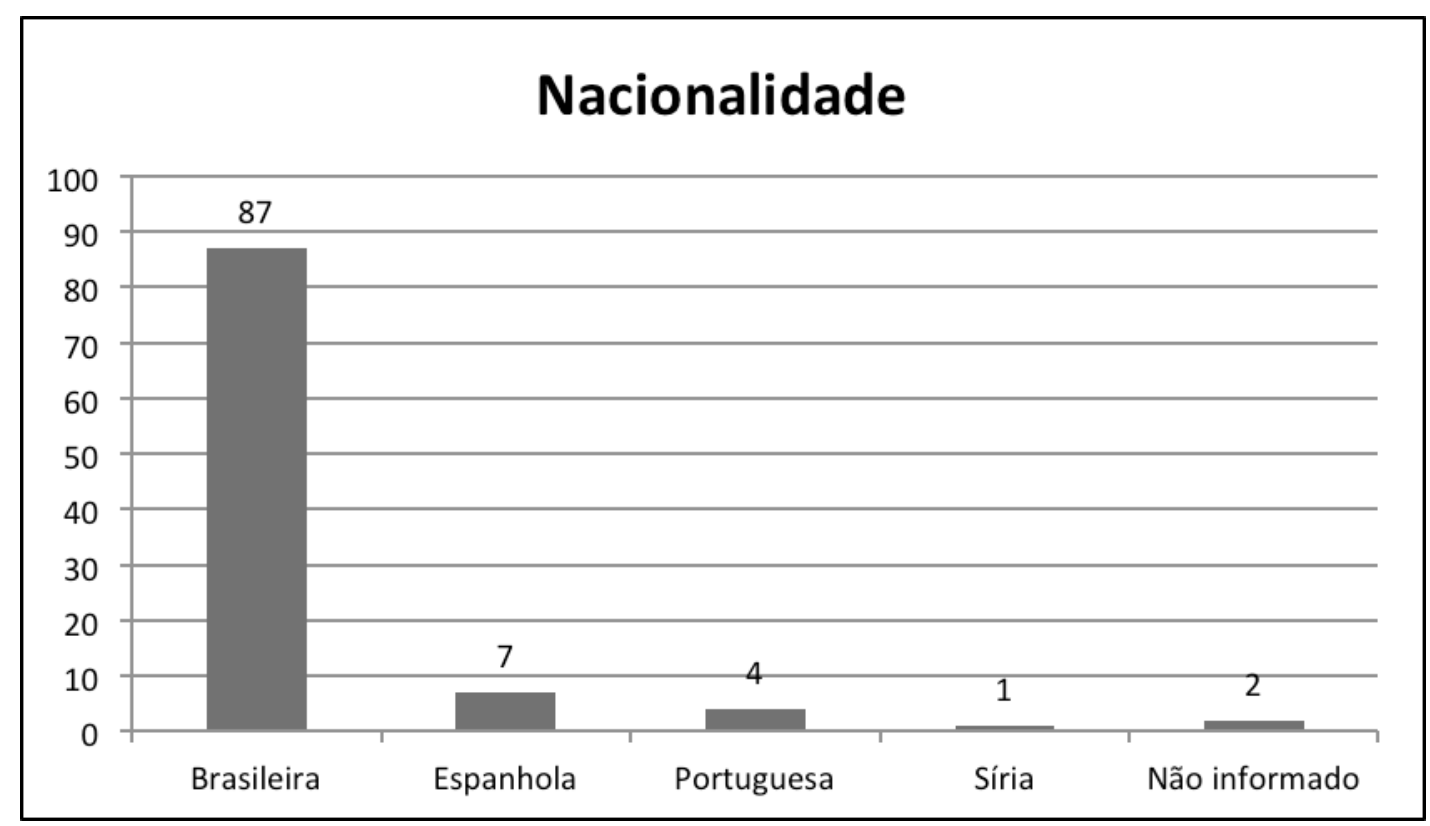

\section{Gráfico 1 - Nacionalidade dos internos/mortos}

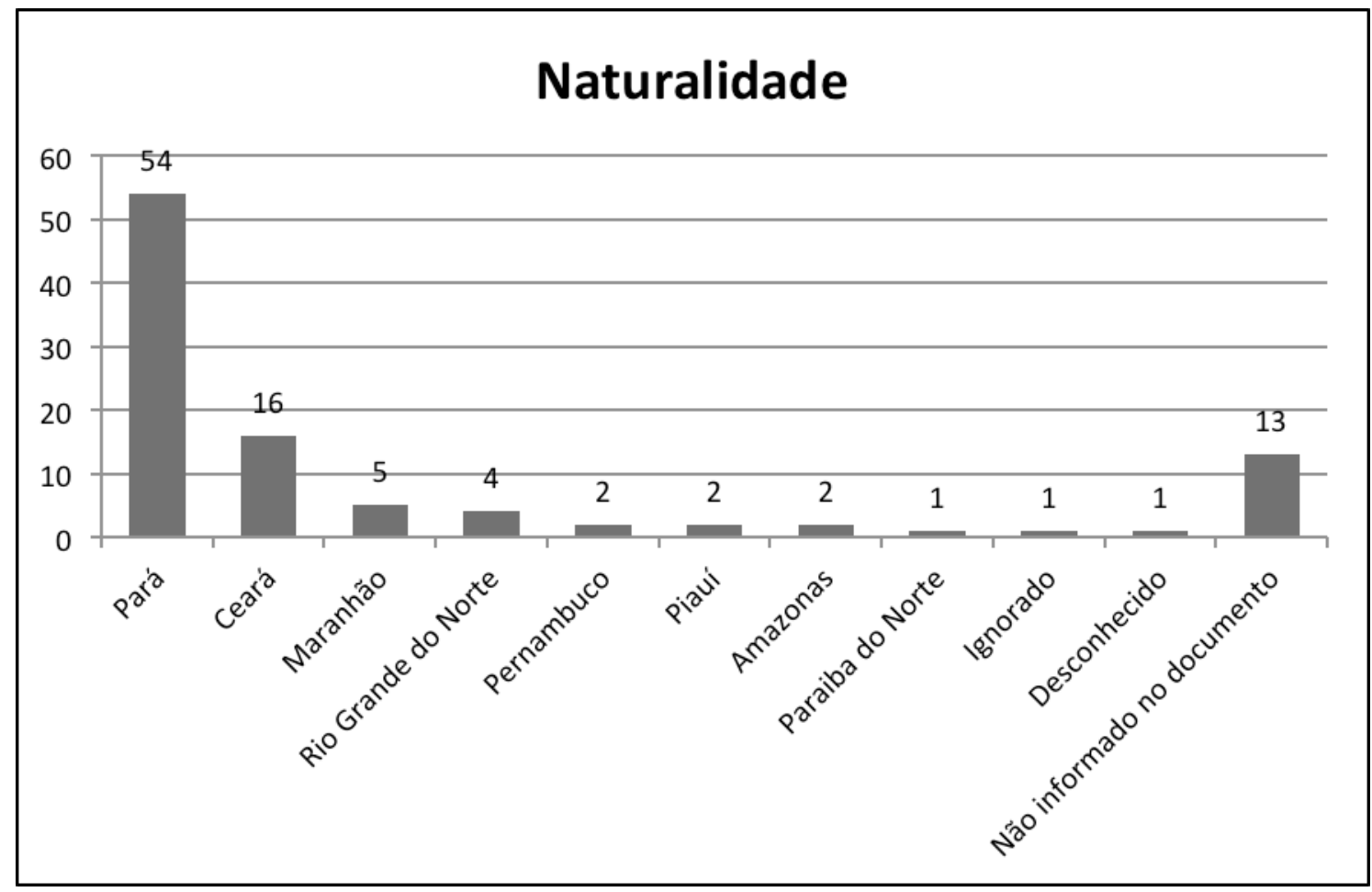

\section{Gráfico 2 - Naturalidade dos internos/mortos}

As definições para etnia apresentam-se bastante estáticas, pré-definidas. Vê-se um quadro diferente dos registros demográficos em tempos de epidemia, por exemplo como é o da Cólera, na segunda metade do século XIX (Beltrão 2004), ou mesmo das demarcações étnicas efetuadas por outros profissionais 
que não relacionados ao campo da saúde para a mesma centúria (Bezerra Neto, 1998 e Baena, 2004 [1885]). Assim, não observamos mais as categorias cabocla (descendentes de negros e índios, de cor morena, cabelos lisos e feições marcadamente indígena), cafuza (ou caburé descendentes de negros ou mulatos e índios, de cor negra, cabelos lisos e grossos), mameluca (descendentes de brancos e índios de cor clara, cabelos lisos e feições supostamente indígenas), mulata (descendente de negros e brancos, cujos traços negros sobressaem), parda (descendente de negros e brancos com pele menos escura), tapuia (denominação genérica dada aos índios destribalizados e, também, as gentes com características consideradas marcadamente indígenas) e, sobretudo, índia (descendentes dos povos originários). Parece que todas as pessoas estão subsumidas na categoria mestiços (Gráfico 3). Aqui nota-se a historicidade desses termos, considerando os diferentes contextos em que eles são usados ou deixados ao largo das categorizações.

A Lazaropólis do Prata era, acima de tudo, o lugar e o tempo do exercício da ciência (Almeida 2007), posto que a própria lepra confrontou o Estado com a necessidade de ações imediatas. Nessa esteira, a medicina ocidental foi a voz de autoridade naquela Instituição, ao modo como vinha ecoando em face a outras práticas curativas correntes (Figueiredo 2003). Logo, as concepções raciais dos oitocentos, difundidas essencialmente por intelectuais ligados à política brasileira (Schwarcz, 1993 e Bezerra Neto, 1998), toma outros contornos, sem, contudo, abolir o método primordial de identificação das raças: a cor da pele.

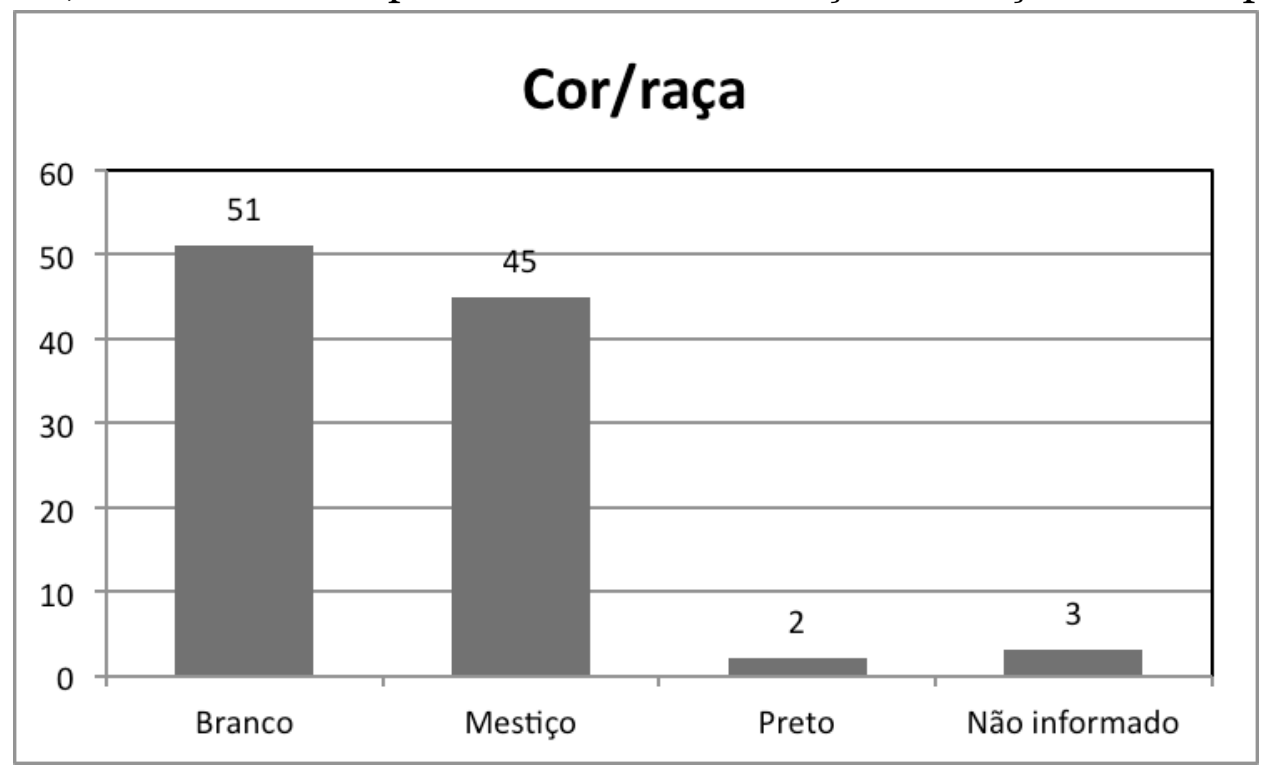

Gráfico 3 - Cor dos internos/mortos

Considerando as Fichas dos doentes do Prata, observamos que o marcador racial considerava a cor da tez, verificada pelo próprio médico durante a avaliação do paciente. Se conversão de pluralidade étnica do século XIX em marcadores estáticos indica, por um lado, a vinculação científica do observador que analisa o fenótipo do paciente, por outro lado, é sugestivo do apagamento da categoria índia e suas derivativas nos registros médicos. Esse fenômeno 
correlaciona-se à política do governo paraense quanto ao seu projeto homogeneizador direcionado aos indígenas. Não por acaso, a partir da extinção do Educandário do Prata, não se observa nos documentos, até então levantados, e, por conseguinte, na literatura que se dedica ao estudo dos seus diversos momentos institucionais, referências aos Tembé Tenetehara. O silêncio talvez refira/esconda o malogro da ação morigeradora.

Os mestiços são, portanto, uma das marcas nas quais foram enquadrados todos os sujeitos que não eram brancos ou pretos; um amálgama, ao que nos parece, de todas as categorias utilizadas no século XIX.

Com os dados referente às faixas etárias, podemos conjugar internos mortos e tempo de permanência no Prata (que, talvez, remonte a época do Núcleo), mas até aqui as mortes são razoavelmente distribuídas por faixa etária. Caso os adultos com mais de 50 anos estivessem no Prata antes da internação, alguns deles poderiam ser indígenas. No caso dos mais jovens, estes poderiam ser filhos de indígenas. De todo modo, entre os dados computados, não há sobrenomes atribuídos aos tembé. Mas não é difícil existirem indígenas entre os internos mortos, até porque as famílias nominadas podem ser as mais resistentes à morigeração e outras pessoas indígenas possam ter sofrido com os apagamentos dos sinais de etnia bem mais cedo - até antes da ida ao Prata, pois os missionários eram incansáveis na busca de ovelhas.

Cabe referir que os tembé se fixaram, após a diáspora inicial, nos campos que compreendiam o Núcleo e suas condições de vida poderiam favorecer a contração da doença. A proporção dos indígenas na área dos lotes das colônias correspondia a até $75 \%$, pois os colonos não-indígenas corresponderiam idealmente a $25 \%$. 


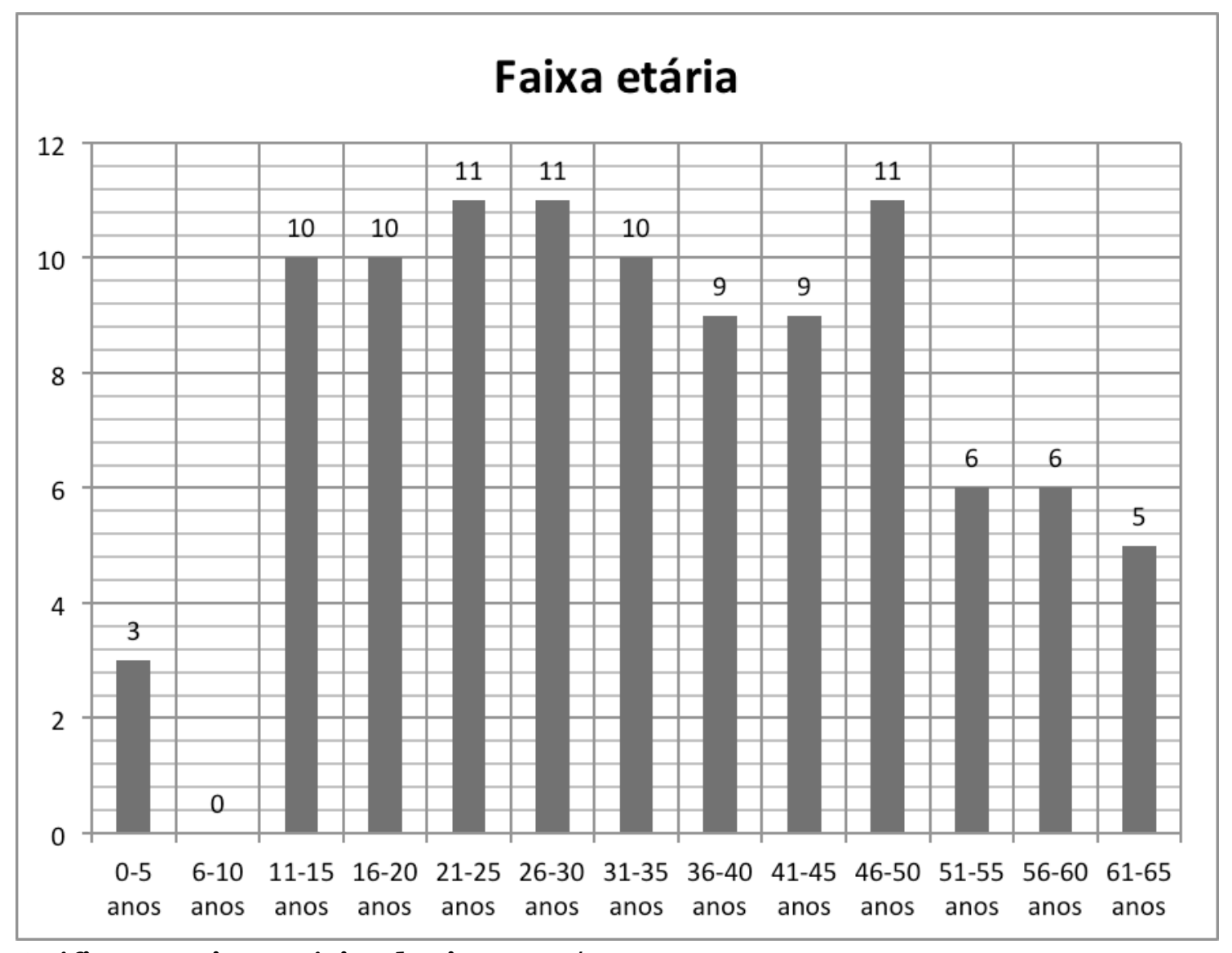

Gráfico 4 - Faixas-etárias dos internos/mortos

\section{Modelo encontrado para pensar práticas coletivas}

O uso do método indiciário, referido por Ginsburg (1990 [1986], 1993 [1975]) para fugir aos incômodos contrapontos entre racionalidade e o irracionalidade, a primeira um atributo europeu e a segunda atribuída aos nãoeuropeus, entre as formas de se expressar historicamente - de forma escrita ou oral - analisa quaisquer indícios como reveladores, ou caminhos e possibilidades de levantar pressupostos relativos às ações do Estado na tentativa de submeter os Tembé. Por outro lado, se a homogeneização não aconteceu, como se deu o enfrentamento organizado pelos indígenas para manter a tradição e minimizar os efeitos das diáporas? $\mathrm{E}$ se houve enfrentamento, como se recria o coletivo ou como se reaprende as práticas coletivas? De que forma, hoje, a partir de histórias articuladas (tradicionais ou não) a projetos de vida (passada e presente) os Tembé se afirmam indígenas?

Para responder estas questões retomam-se tanto as histórias Tembé, como as marcas que se apresentam na documentação do antigo Núcleo como étnicas, forte ou sutilmente sublinhadas, nos documentos e no quotidiano observável, pela diferença que produzem em relação aos vizinhos não-indígenas que cercam os pequenos territórios que os Tembé conseguiram preservar.

Ao juntar pontos residuais da malha tecida produziu-se um conhecimento indireto e conjectural sobre o que é "viver melhor" para os Tembé de Santa Maria. 
É sabido que os povos indígenas são exímios conhecedores da floresta e que possuem capacidade de ler a natureza, quando criados na tradição, no sistema indígena como referiram Miguel e Almir em suas narrativas. Assim sendo, comportam-se como estrategistas e ao longo de mais de um século, entre diásporas e esbulho de seus territórios, mantiveram na memória dos mais velhos a possibilidade de ser Tembé. Os velhos são patrimônio e conduzem politicamente os destinos do povo.

Para bem viver, o modelo é: (1) cultivar a tradição - caso esta esteja demasiadamente esfumaçada, recorrer aos parentes; (2) pensar as narrativas como ensinamentos para viver em comunidade; (3) partilhar tradições que devem ser reavivadas quotidianamente; (4) reivindicar o território confiscado para ampliar os circunscritos espaços de hoje; (5) exigir a demarcação de suas terras; e (6) inscrever-se na história reafirmando sua identidade.

O modelo ainda parece-nos incompleto, mas na medida em que os indícios vão sendo reunidos a complexidade do modelo deve reaparecer. Por outro lado, é importante ver o modelo homogeneizador em ação para melhor compreender os estrategistas tembé. 


\section{Referências \\ Fontes documentais \\ Manuscritas}

Registro dos Attestados de Obitos ocorridos na Lazaropolis do Prata.

Depoimentos e Narrativas Tembé, registradas entre 2009 e 2013.

Entrevistas realizadas com os Tembé, entre 2009 e 2013.

Fichas/Prontuários da Colônia Santo Antônio do Prata.

Documentos relativos aos Processos Seletivos Especiais para povos indígenas (2010, 2011, 2012 e 2013) realizados pela Universidade Federal do Pará.

Silva, Almir Vital da; Fernandes, Edimar A. \& Beltrão, Jane Felipe. 2012. Histórias, Narrativas e Cuidados à Saúde entre os Tembé. Relatório de Iniciação Científica/CNPq/UFPA. (Manuscrito inédito).

Tembé. 2011. Relatório apresentado à Fundação Brasil de Direitos Humanos. Santa Maria do Pará. (Documento inédito).

\section{Impressas}

Baena, A. L. M. 2004[1885]. Ensaio Corográfico sobre a Província do Pará. Brasília, Senado Federal. (Fonte impressa).

Muniz, João de Palma. 1913. O Instituto de Santo Antonio do Prata (Município de Igarapé-Assú). Belém: Typ. da Livraria Escolar. (Fonte Impressa).

\section{Bibliográficas}

Almeida, B. L. C. d.. A profilaxia da Lepra no estado do Pará: o contexto da fundação da Lazarópolis do Prata (1920-1925). Monografia de Graduação. Faculdade de História, Universidade Federal do Pará, 2007. (Manuscrito inédito).

Barth, Fredrik. (LASK, Tomke org.). O guru, o iniciador e outras variações antropológicas. Rio de Janeiro, Contra Capa, 2000. 
Beltrão, Jane Felipe. Cólera, o flagelo da Belém do Grão-Pará. Coleção Eduardo Galvão. Belém, Museu Paraense Emílio Goeldi/Universidade Federal do Pará, 2004.

"Histórias em suspenso, os Tembé de Santa Maria . Estratégias de enfrentamento do etnocídio cordial" In Revista História Hoje, v. 1, 2012: pp. 195-212.

Amazônicos, 2012.

Povos Indígenas na Amazônia. Belém-Pará, Estudos . "Reduzidos sim, vencidos nunca": identidades, histórias, memórias e patrimônio entre os Tembé Tenetehara" In Coelho, Wilma de Nazaré Baía \& Coelho, Mauro Cezar (Orgs.). Trajetórias da Diversidade na Educação: formação, patrimônio e identidade. São Paulo-SP: Livraria da Física, 2012: pp. 51-84.

Benbassa, Esther. Dictionaire des racismes, d'exclusion et des discriminations. Rodesa/Espanha, Larousse, 2010.

Bezerra Neto, José Maia. "O homem que veio de Óbidos, pensamento social e etnográfico em José Veríssimo” In Anais do Arquivo Público do Pará 3 (2): 1998: pp.239-261.

Cardoso, Maria Helena Cabral de Almeida. "História e Medicina: herança arcaica de um paradigma" In História, Ciências, Saúde. VI (3): 2000: pp. 551-575.

Fernandes, Edimar Antonio; Silva, Almir Vital da \& Beltrão, Jane Felipe. "Associação Indígena Tembé de Santa Maria do Pará (AITESAMPA) em luta por direitos étnicos" In Amazônica: Revista de Antropologia. v. 2, 2011: pp. 392406.

Figueiredo, Aldrin Moura de.. "Anfiteatro da cura: Pajelança e medicina na Amazônia no limiar do século XX" In Artes e ofícios de curar no Brasil: Capítulos de história social. Editado por Marques, Vera R. B. ; Chalhoub, Sidney; Sampaio, Gabriela d. R.; \& Sobrinho, C. R. G. Campinas, EdUNICAMP, 2003: pp. 273-304.

Ginzburg, Carlo. Mitos, Emblemas, Sinais: Morfologia e História. São Paulo, Companhia das Letras, 1990 [1986].

O queijo e os vermes: o cotidiano e as ideias de um moleiro perseguido pela Inquisição. São Paulo, Companhia das Letras, 1993 [1976]. 
Gnerre, Maurizio. Linguagem, escrita e poder. São Paulo, Martins Fontes, 2033 .

Goody, Jack. Domesticação do Pensamento Selvagem. Lisboa, Editorial Presença, 1988.

Lévi-Strauss, Claude. O Pensamento Selvagem. São Paulo, Editora Nacional/USP, 1970. [1962].

Oliveira, João Pacheco. "Entrando e saindo da "mistura": os índios nos censos nacionais" In Ensaios de Antropologia Histórica. Rio de Janeiro, Editora UFRJ, 1999.

Schwarcz, Lilia Moritz. O espetáculo das raças. São Paulo, Companhia das Letras, 1993.

Wright, Robin M.. História indígena e indigenismo no Alto Rio Negro. Campinas/São Paulo, Mercado de Letras/ISA, 2005. 